\title{
On the Content of Information Systems Ontologies
}

\author{
Timothy Tambassi ${ }^{1}$ (D)
}

Received: 21 October 2020 / Accepted: 18 March 2021 / Published online: 9 April 2021

(c) The Author(s) 2021

\begin{abstract}
Despite the fact that information systems ontologies [ISOs] support the mutual understanding between human beings and software applications, human beings and software applications do not understand ISOs' contents in the same way. The same applies to ontological integration. This paper attempts to account for such discrepancies by emphasizing that while human being can have access to entities represented in ISOs, software applications cannot.
\end{abstract}

Keywords Information systems ontologies $\cdot$ Mutual understanding · Ontological integration

\section{Ontology in Information Systems}

According to Smith (2003), information systems ontologists generally share the assumption that

[1] ontology does not deal with reality but with alternative possible worlds defined by information systems.

On one side, this means that ontologists reject the definition of ontology coming from the (analytical) philosophical investigation, according to which ontology aims to draw a complete inventory of reality by specifying its fundamental structure. ${ }^{1}$ On the other side, they embrace the definition of ontologies coming from the IT domain, suggesting that:

- ontology refers to an explicit (and sometimes partial) specification of a shared conceptualization that is formalized in a logical theory, ${ }^{2}$

\footnotetext{
1 Lowe (2006).

2 Guarino et al. (2009).

Timothy Tambassi

timothy.tambassi@gmail.com

1 Department of Science of Cultural Heritage, DISPAC, University of Salerno, via Giovanni Paolo II, 13284084 Fisciano, SA, Italy
} 
- speaking of ontologies, in the plural, indicates a multiplicity of artificial worlds defined by information systems ontologies [ISOs] as well as different ways to represent such worlds. ${ }^{3}$

Now,

[2] outlining an ISO's world means providing an inventory of all the entities (in primis, classes, instances, and relations ${ }^{4}$ ) that populate such a world.

The ontological implications of this operation, Smith holds, are essentially two:

[3] only those entities exist which are represented in the ISO,

[4] the entities in question possess only those properties which the ISO itself recognizes.

According to Smith, [4] suggests an analogy between fictional and ISOs entities. «It is as if Hamlet, whose hair (we shall suppose) is not mentioned in Shakespeare's play, would be not merely neither bald nor nonbald, but would somehow have no properties at all as far as hair is concerned» ${ }^{5}$ (Smith, 2003: 161). This means that, as well as for fiction,

[5] the entities represented in an ISO are not real entities - the entities of flesh and blood we find all around us.

Rather,

[6] they are denatured surrogates,

[6.1] possessing only a finite number of properties,

[6.2] being entirely indeterminate with regard to those properties with which the ISO is not concerned.

\footnotetext{
3 Couclelis (2019).

4 Laurini (2017).

5 While by discussing Smith's proposal in terms of ISOs' completeness (see [2]) and analogy between fictional and ISOs' entities, this paper can be interpreted as an analysis of the consequences of such a proposal, it should also be noted that both [2] and the analogy are not accepted by the entire community of computer scientists. Indeed, with regard to [2], some IT/computer approaches assume the incompleteness of ISOs' conceptualizations-especially for the ISOs within the Web environment. More precisely, for those ISOs, the incompleteness is formally stated as the Open-world assumption, according to which everything that cannot be inferred as false from an ISO must be considered unknown. This means that, for these cases, [2] does not hold and, consequently, [3] and [4] should be retracted. As regards to the analogy between fictional and ISOs' entities, some IT/computer scientists refuse such an analogy, and consider ISOs' entities as symbolic representations of conceptualizations of world fragments. According to this perspective, ISOs' entities are still denatured surrogates but also abstractions that can be refined by means of integration (see $\S 3$ ). Therefore, if it may be a non-sense to wonder about Hamlet's hair; it does make sense to integrate ISOs' contents with contents coming from other ISOs-possibly, through a refinement of the abstractions provided by their conceptualizations.
} 
However, as regards to [3], the analogy between ISO and fiction shows a discrepancy. If it is true that, in the domain of ISOs, only those entities exist which are represented in the system, there are cases, ${ }^{6}$ in the realm of fiction, where we might also assume the existence of entities that are not mentioned in the fiction itself. For example, while the city of Cremona does not exist in TV shows such as Game of Thrones and Teletubbies, we cannot exclude its existence in William's novel Stoner or Manzoni's I promessi sposi, although "Cremona" is never mentioned in these novels.

\section{Internal and External Questions}

We might now consider the example of

[7] an ISO representing all the countries in the world and apply to it

[8] Carnap's (1950) distinction between internal and external questions.

Varzi (2009: 6) explains such a distinction as follows: a question is internal to a framework (in our case, an ISO) if it may get answered by the resources provided by the framework; a question is external if it refers to the acceptability of the framework itself. Therefore, asking about the existence of a certain country is a question internal to [7] in so far as it concerns the existence of that country in relation to [7]. As opposed to this, asking whether countries really exist is an external question, as it concerns the reality of the world presupposed by [7], but then, what are those entities that populate [7]? According to [5] and [6], such entities are not the real countries where we live or that we can visit in our everyday life. Rather, they are merely representations (denatured surrogates, in Smith's terms) of the real countries we have all around us. This means that internal questions involve the denatured surrogates (of the entities of the real world) represented in [7]. On the contrary, external questions refer to the real world whose entities are represented in [7] by surrogates.

The choice of introducing [8] is not random. Indeed, speaking of ISOs' contents, Goy and Magro (2015) argue that

[9] ISOs can support the mutual understanding between human beings, between human beings and software applications, and between software applications themselves.

This does not, however, imply that human beings and software applications understand ISOs' contents in the same way, but if so, what does the difference involve? To answer this question, I find it is crucial to consider that, while human beings may have access to the objects represented in ISOs' contents (i.e., the references of ISOs' contents in the real world), software applications may not. This implies that the mutual understanding between software applications is anchored to ISOs' contents in terms of [6], whereas the mutual understanding between human

${ }^{6}$ Lewis (1978). 
beings can refer to both ISOs' contents and to the correspondence between ISOs' contents and the real world. In other words, human beings are in the position to address external questions.

\section{ISO Integrations}

The mutual understanding mentioned in [9] is strictly intertwined with the notion of ISO integration. More precisely, Goy and Magro maintain that the possibility for software applications of understanding ISOs' contents enables data integration on the Web. What is ISO integration, then? Broadly speaking,

[10] ISO integration is the process by which ISOs can semantically combine data from multiple heterogeneous information systems. ${ }^{7}$

Such a process is related to the general aims of ISOs including the description of semantic heterogeneity in different information sources and the formulation of unambiguous definitions and identifications for their entities.

Now, if Smith is right in endorsing the analogy between fictional and ISOs entities, we might ask, as fiction theory does:

[11] how and to what extent are we entitled to integrate ISOs' contents?

A possible answer to [11] could result from [3^4]: if only those entities exist which are represented in an ISO and such entities only possess the properties that the ISO itself recognizes, then integrations are not possible. Another answer may derive from [ $\left.6^{\wedge} 10\right]$, according to which, if ISOs can semantically combine data from multiple information systems, then ISOs' contents may be integrated with data coming from other information systems - data that, according to [6], are in turn denatured surrogates.

However, fiction theory does not see things in the same way. It is not just the integration from other fictions to be interesting - that is, applying [10] to fiction theory. Rather, it is

[12] the possibility to integrate what it is explicitly stipulated in a fiction with what might legitimately be considered to be true within that fiction.

How to do that? For example, we could follow the reality principle [RP] and the mutual belief principle [MBP].

RP says that a fictional world is as much as like the real world as the explicitly stipulated fictional truths permit.

\footnotetext{
${ }^{7}$ Li et al. (2018).
} 
MBP says that it is not reality that licenses integrations, but the common beliefs shared at the time the fiction has been written. ${ }^{8}$

Now, without taking into account any criticism of such principles, there are at least four different reasons that make the introduction of RP and MBP in the debate on ISO integration problematic, namely: [1], [3^4], [6^10], and [2^3].

[1] is specifically directed against RP: if ISOs do not deal with reality, why integrate ISOs' contents with the real world? [3^4], [6^10], and [2^3] are instead addressed against both RP and MBP. [ $\left.3^{\wedge} 4\right]$ excludes any integration, including those from RP and MBP. [6^10] allows only integrations from information systems. Finally, while both RP and MBP seem to presuppose, according to [12] that a (fictional) world might be more crowded compared to what has been explicitly stipulated, [2^3] seems to say otherwise.

\section{Integrations and External Questions}

But then, why should we introduce RP and MBP in the debate on ISO integration? Because of external questions, which, I suggest, could enrich the possibilities of ISO integration.

Let's take [7] again, specifying that

[13] it only represents all the countries in the world,

[14] it does not recognize the property "has as capital."

Based on [ $\left.3^{\wedge} 13\right]$, we can say that only all the countries of the world exist in [7]; based on $\left[5^{\wedge} 6\right]$ that those countries are not the real countries but their denatured surrogates; based on [ $\left.4^{\wedge} 14\right]$ that those denatured surrogates do not possess the property "has as capital"- -although the real countries possess such a property.

Now, according to Parsons (1980) for fiction entities and to Smith for ISOs' ones (see [6.2]), we should maintain that, as regards to the property "has as capital," [7]'s countries are indeterminate. However, I suggest, such an indeterminacy improperly refers to [7]'s countries, given that [7] itself does not take into account the property "has as capital." Rather, [7]'s countries are indeterminate about the property "has as capital" if compared to the real world whose countries possess such a property.

Accepting such a line of reasoning means that

[15] the indeterminacy mentioned in [6.2] implies a relation between ISOs' contents and the world represented by the ISOs.

If so, a chance to make [7]'s entities determinate about the property "has as capital" might consist in integrating [7]'s entities with the property "has as capital" that the real countries possess, but then, integrations from the (external) world represented by [7] would be, at least in principle, possible. To what

\footnotetext{
${ }^{8}$ Walton (1990).
} 
extent? The analogy between fictional and ISOs entities might suggest to follow, for example, RP or MBP, that is — as explicitly stipulated in [7]_integrating [7]'s contents with, for example, the real world, or with the real world at the time [7] has been created, or with the beliefs shared by the ontologists who wrote [7] at the time [7] has been created, and so forth, and this is how and to what extent external questions enrich the possibilities of ISO integration.

Accordingly, facing [11] requires to specify whether answering

[16] by the (internal) resources provided by ISOs,

[17] by the (external) world represented in ISOs by denatured surrogates.

Outlining such alternatives does not imply that human beings and software applications could integrate ISOs' contents in the same way. As it happens with [9], the difference refers to the fact that human beings have access to the external world represented in the ISOs by denatured surrogates whereas software applications have not. Therefore, we might conclude by observing that, while for software applications ISO integrations are tied to [16], human beings can integrate ISOs' contents in terms of [16] and [17]. This might also explain why when we look at ISOs' contents we, as human beings, do not see just denatured surrogates but also the entities represented in the ISOs.

Funding Open access funding provided by Università degli Studi di Salerno within the CRUI-CARE Agreement.

\section{Declarations}

Competing Interests The authors declare no competing interests.

Open Access This article is licensed under a Creative Commons Attribution 4.0 International License, which permits use, sharing, adaptation, distribution and reproduction in any medium or format, as long as you give appropriate credit to the original author(s) and the source, provide a link to the Creative Commons licence, and indicate if changes were made. The images or other third party material in this article are included in the article's Creative Commons licence, unless indicated otherwise in a credit line to the material. If material is not included in the article's Creative Commons licence and your intended use is not permitted by statutory regulation or exceeds the permitted use, you will need to obtain permission directly from the copyright holder. To view a copy of this licence, visit http://creativecommons.org/licen ses/by/4.0/.

\section{References}

Carnap, R. (1950). Empiricism, semantics, and ontology. Revue Internationale de Philosophie, 4, 20-40.

Couclelis, H. (2019). Unpacking the "I" in GIS: Information, ontology, and the geographic world. In T. Tambassi (Ed.), The Philosophy of GIS. (pp. 3-24). Springer.

Goy, A., Magro, D. (2015). What are ontologies useful for? In M. Khosrow-Pour (ed.), Encyclopedia of information science and technology. IGI Global, 7456-64. 
Guarino, N., Oberle, D., \& Staab, S. (2009). What Is an Ontology? In S. Staab \& R. Studer (Eds.), Handbook on Ontologies. (pp. 1-17). Springer.

Laurini, R. (2017). Geographic knowledge infrastructure: Applications to territorial intelligence and smart cities. ISTE-Elsevier.

Lewis, D. (1978). Truth in fiction. American Philosophical Quarterly, 15(1), 37-46.

Li, X., Wu, Z., Goh, M., \& Qiu, S. (2018). Ontological knowledge integration and sharing for collaborative product development. International Journal of Computer Integrated Manufacturing, 31(3), 275-288.

Lowe, E. J. (2006). The four-category ontology: A metaphysical foundation for natural science. Clarendon Press.

Parsons, T. (1980). Nonexistent Objects. Yale University Press.

Smith, B. (2003). Ontology. In L. Floridi (Ed.), Blackwell guide to the philosophy of computing and information. (pp. 155-166). Blackwell.

Varzi, A. (2009). Metafisica: classici contemporanei. (p. 2018). Laterza.

Walton, K. (1990). Mimesis as make-believe: On the foundations of the representational arts. Harvard University Press.

Publisher's Note Springer Nature remains neutral with regard to jurisdictional claims in published maps and institutional affiliations. 